\title{
Comparative Study of Cervical Pap Smear and Visual Inspection of The Cervix To Detect Premalignant Disease of The Cervix
}

\author{
Rozhan Yassin Khalil \\ Obstetrics \& Gynecology Department \\ College of Medicine \\ Sulaimani University \\ Sulaimani, Iraq \\ rozhan.khalil@univsul.edu.iq
}

\author{
Khanda Abdolrahman Qader \\ Obstetrics \& Gynecology Department \\ Sulaimani General Directorate of Health \\ Ministry of Health \\ Sulaimani, Iraq \\ khandaabdolrahman@yahoo.com
}

\section{Article Info \\ Volume 5 - Issue 1 - June 2020 \\ DOI: \\ 10.24017/science.2020.1.15 \\ Article history: \\ Received : 03 February 2020 Accepted : 15 June 2020}

Keywords:

Pap Smear,

Premalignant Disease Of Cervix,

Visual Inspection,

Acetic Acid,

Cervical Cancer.

\section{ABSTRACT}

The goal of current study is to compare visual inspection method of the cervix by using acetic acid sensitivity, specificity, positive and negative predictive values with Pap smear test values. This cross sectional study was obtained in Sulaimani city Kurdistan region at Maternity Teaching Hospital throughout the period (first September 2012) to (first February 2001). This study include 115 samples were reproductive women and premenopausal between ages 20-50 years old with symptomatic women ( vaginal discharge, dyspareunia, post coital bleeding, intermenestrual bleeding) and prepared patients for a Pap smear test done for them.

The cervix was painted with 5\% concentration of acetic fluid for visual inspection method and monitored for aceto-white wounds and biopsies were taken from suspected areas. After that, the samples in $95 \%$ concentration of the ethyl alcohol were fixed. The results shows that, 114 samples among all other samples were appropriate for analyzing, statistical data analyzed by Epi Info software program and Chi-squared test used to find significance between variables with considering P-value less or lower than 0.05 as significant level. The result indicate that sensitivity rate was $16 \%$ for visual inspection method, specificity $71 \%$, positive predictive value $3.13 \%$ and negative predictive value $93.9 \%$ to detect pre-cancerous lesion of the cervix. In conclusion, cervix visual inspection method for cancer had a low rate sensitivity compare with pap smear with a non-significant relationship between the two methods and Pap smear needed to conform visual inspection for cervical cancer.

Copyright $@ 2020$ Kurdistan Journal of Applied Research. All rights reserved. 


\section{INTRODUCTION}

Non communicable diseases problem in developing countries become more and more due to lack of proper and effective program to control it, one of this non communicable diseases are cancer. According to GLOBOCAN 2012 report cervical cancer in a list of all cancers in women is fourth and seventh in all cancer worldwide with estimate 528,000 new cases. In addition, mortality of cervical cancer approximately 266,000 deaths occurred worldwide in 2012 while in the developing countries were $(445,000$ cases), it rank in the second frequent cancer and in the developed areas rank in 11th (83,000 cases). Also, in less developed regions nearly nine in $10(87 \%)$ deaths occur in the cervical cancer cases, which is make cervical cancer the most frequent cancer among women in the Middle and Eastern Africa [1]. Cervical cancer deaths in the middle of the 20th century among women at the United States was most repeated cause of cancer death, now it is at 14th ranks for cancer deaths [2]. The decrease of cervical cancer mortality was due to; detection in early stages of cancer increased and detection and treatment of pre-invasive cervix lesions, over all reduces the incidence of invasive cancer [3]. High mortality rate of cervical cancer among developing areas mostly related to that cervical cancer diagnosed in third and fourth cancer stages and absence of good and organized screening tests [4].

Persistent cervical infection is necessary involve human papillomavirus (HPV) infection to develop cervical cancer, studies stated that HPV were positive in near in all cervical cancer cases and HPV type 16 (HPV16) responsible of 55\% to $60 \%$ of all cervical cancers [5]. Most histological subtypes of all cervical cancers are Squamous cell carcinoma which is responsible of $70 \%$ cervical cancer and adenocarcinoma are responsible of $25 \%$ cervical cancer [6]. Cervical cancer progress from long term of precancerous wounds that could effectively diagnosed with screening and controlled only by treatment can be effectively cured [1]. Microscopic examination of Pap smears to detect cytological abnormalities and subsequent treatment avoids development of cancer [7].

Beside human papillomavirus factor there are many other main risk factors that may increase risk of cervical cancer to occur which are multiple sexual partner, history of sexual transmitted diseases (STD), immunosuppression, sex debut in early age, not participate in a screening or living in area lack of good screening program and smoking tobacco [8].

Pap smear is the traditional Papanicolaou (Pap) smear which described in 1943 by Dr.George papanicolaou, which identify intraepithelial neoplastic lesions or atypical squamous cell in the cervix [9]. Cytology-based prevention programs is difficult to imply in developing countries because they do not have enough resources, which need well organized laboratories and specialized personnel [10]. Newer approaches include Pap smear are expensive, timeconsuming and not widely available, therefore other alternative screen tests used in limited resources areas for example visual inspection (VIA) method by using acetic acid which is a simple low-cost technique because cervix easily accessed. Some studies suggest that VIA match the Pap smear for detecting cervical cancer performance [11]. VIA based on health care trained ability to detect aceto white in the cervical transformation zone [12].

Cervical cancer can be treated by surgery, chemotherapy and radiation, or use mixture of these methods with consideration the site of recurrence, kind of primary treatment, the patient symptoms, duration of disease-free, performance status and the beneficial degree of given treatment [13].

The goal of the current study is to compare the visual inspection method of the cervix with using acetic acid sensitivity value, specificity value, positive predictive value and negative predictive value with Pap smear values to predict pre-cancerous lesion of the cervix. 


\section{METHODS AND MATERIALS}

It is cross-section study, samples collected in Sulaimani maternity teaching hospital in Sulaimani city Kurdistan region during six months period from first September 2012 to first February 2013, in every working day, This study included 115 women were referred from the clinic by gynaecologist to the hospital and examined in consultation unit were detailed history was taken women put in dorsal position, For the cervix visual method inspection using bivalves speculum (Cusco speculum) without using disinfectant to not affect the result, cervix were painted by researcher using $5 \%$ concentration of acetic fluid and after that looking for aceto-white wounds. In addition, researcher taken Pap smear samples of suspected areas biopsied then obtained samples in $95 \%$ ethyl alcohol concentration were fixed to take into the Pathology Department and checked by the same pathologist.

The inclusions criteria include: reproductive women between ages 20-50 years old with symptomatic women ( vaginal discharge, dyspareunia, post coital bleeding, inter menstrual bleeding) and prepared patients for a Pap smear test. In addition, the exclusion cases: were pregnant women, vaginal bleeding, people with obvious growth of cervix, those who transformation zone not seen.

Preparation of cervix visual inspection and Pap smear: dorsal position was choose for each woman for taking sample with her lower limb bended at the hip and knee, the labia were separated by using index and thumb fingers, all genitalia and the perineal area were inspected, no any visible lesion like wart was observed. The Cusco's bivalve speculum passed and fixed to see the cervix which was not lubricated under an intense light lamp. The end of the Ayres' spatula then inserted at the external Os and to scrape the all squamocolumnar junction swept $360^{\circ}$ rotatory movement either in a clockwise or anticlockwise direction. The smears were equally spread on two pre-labelled frosted slides and immediately immersed into $95 \%$ alcohol concentration for fixation.

Questionnaire forum used to record patients demographic data, tests result and medical history like used and type of contraception method, per cent of vaginal discharge, postcoital bleeding, Inter menstrual bleeding, Dysparunia, immune compromise, smoking and history of first labour, ethical approval taken from maternity hospital and women acceptant taken verbaly.

Data entered to Microsoft Excel spreadsheet with Identity number (ID) for each questionnaire forum and analyzed by Epi Info software program for statistical analysis, to calculate frequency and percentage on table or charts and Chi-squared test obtained to find significances of the correlation between variables, $0.05 \mathrm{P}$-value considered as a significant level.

\section{RESULTS}

A number of 115 women in the age ranged from 20 to 50 years old with mean and standard deviation (SD) (35.3 \pm 7.389 ), parity was ranged 0 to 8 with $3.3 \pm 1.651$ mean and SD, Most the women were from urban area $80(70 \%)$ than rural $34(30 \%)$ and majority of women were housewife $99(87 \%)$ while employer 5(4\%) were less and women teacher were $10(9 \%)$ were conducted this study.

Most of the women at age group (30-39) years old followed by 40-50 years and minimum numbers were at 20-29 years old group. 


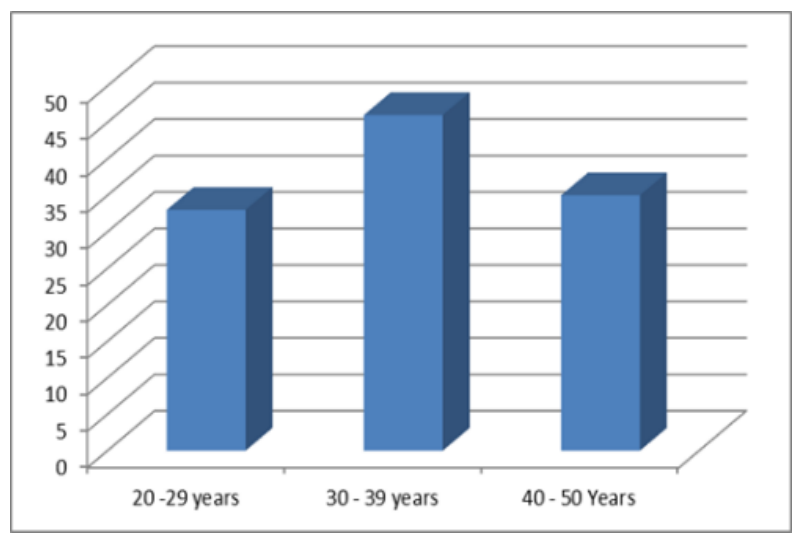

Figure 1: Age groups of patients

Majority of women in this study married at 16-20 years old and followed by 21-23 years old, 11-15 years old lower or equal than 26 years old respectively, while were less in 11-15 years old group and mean and SD duration of marriage were 19.04 \pm 3.966 .

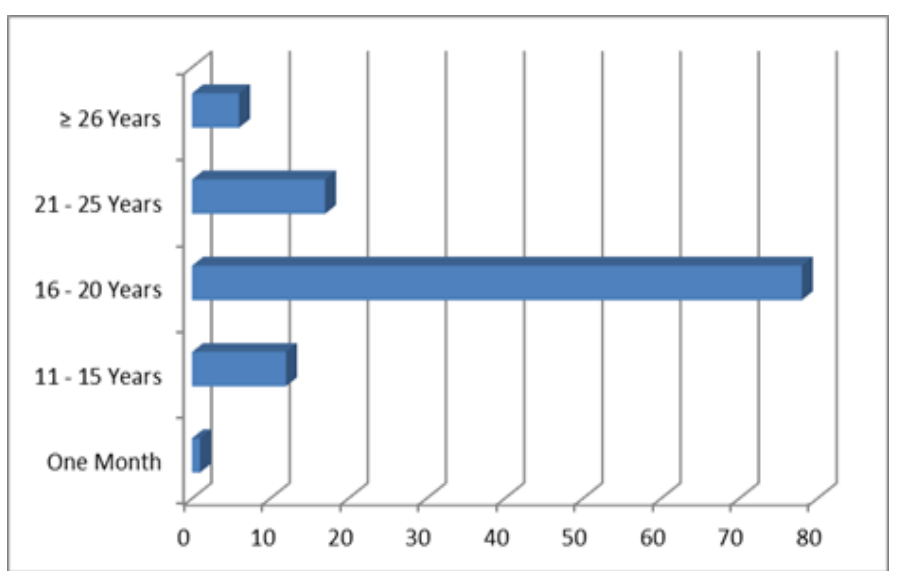

Figure 2: Patients age groups of marriage

Women who gave birth were major $98 \%$ and from this rate, $42 \%$ of them gave 3-4 births, $35 \%$ gave $1-2$ births and $21 \%$ gave 5 or more birth prospectively.

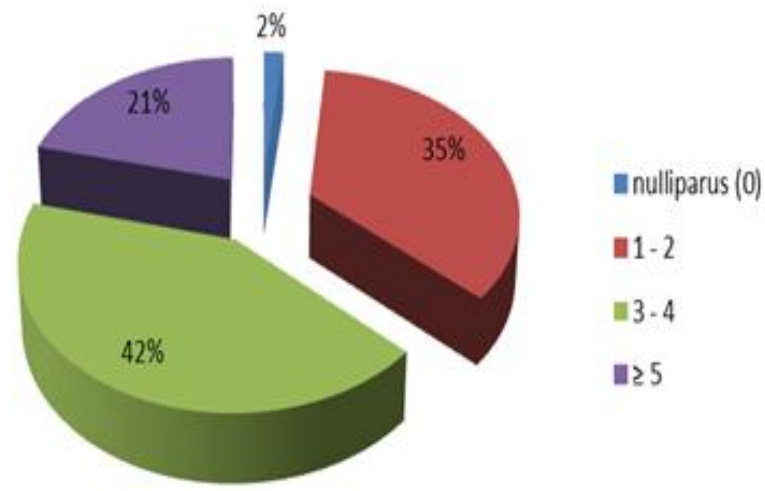

Figure 3: Frequency of given birth number groups

Natural contraceptive method $52(45.2 \%)$ women were more than un natural way ( IUCD, contraceptive pill) $61(53.5 \%)$ and ICUD 41 (36\%) women users were more comparable to Pill 
$20(17.5 \%)$ women users in Un natural contraception methods. Majority of women did not have post-coital bleeding $102(89.5 \%)$, Dysparunia $79(69.3 \%)$ and Intermenstrual bleeding 107 (93.9\%), however, most women had vaginal discharge $97(85.1 \%)$.

Table1: Frequency distribution of the studied sample to some clinical features.

\begin{tabular}{|c|c|c|c|}
\hline \multicolumn{3}{|c|}{ Variable } & $\begin{array}{l}\text { Frequency } \\
(\%)\end{array}$ \\
\hline \multirow[t]{4}{*}{ Contraception } & None & & $1(0.9 \%)$ \\
\hline & \multirow{2}{*}{$\begin{array}{l}\text { Unnatural } \\
\text { Contraception }\end{array}$} & IUCD & $41(36 \%)$ \\
\hline & & Pills & $20(17.5 \%)$ \\
\hline & \multicolumn{2}{|l|}{$\begin{array}{l}\text { Natural } \\
\text { Contraception }\end{array}$} & $52(45.6 \%)$ \\
\hline \multirow{2}{*}{$\begin{array}{l}\text { Post-coital } \\
\text { bleeding }\end{array}$} & \multicolumn{2}{|l|}{ Yes } & $12(10.5 \%)$ \\
\hline & \multicolumn{2}{|l|}{ No } & $102(89.5 \%)$ \\
\hline \multirow{2}{*}{ Dysparunia } & \multicolumn{2}{|l|}{ Yes } & $35(30.7 \%)$ \\
\hline & \multicolumn{2}{|l|}{ No } & $79(69.3 \%)$ \\
\hline \multirow{2}{*}{$\begin{array}{l}\text { Intermenstrual } \\
\text { bleeding }\end{array}$} & \multicolumn{2}{|l|}{ Yes } & $7(6.1 \%)$ \\
\hline & \multicolumn{2}{|l|}{$\mathrm{No}$} & $107(93.9 \%)$ \\
\hline \multirow{2}{*}{$\begin{array}{l}\text { Vaginal } \\
\text { discharge }\end{array}$} & \multicolumn{2}{|l|}{ Yes } & $97(85.1 \%)$ \\
\hline & \multicolumn{2}{|l|}{ No } & $17(14.9 \%)$ \\
\hline
\end{tabular}

Most women in visual inspection were negative $82(71.9 \%)$ for observation of cervical cancer compare to positive cases $(32$ (28.1\%) of cervical cancer in total 114 cases.

Table 2: Result of visual inspection method

\begin{tabular}{ll}
\hline \multicolumn{1}{c}{ Visual Inspection } & \multicolumn{1}{c}{ Frequency (\%) } \\
\hline Negative & $82(71.9 \%)$ \\
\hline Positive & $32(28.1 \%)$ \\
\hline Total & $114(100 \%)$ \\
\hline
\end{tabular}

Pap smear by Bethesda system on studied women shows that $88(77.2 \%)$ women had infection, $14(12.3 \%)$ women had Metaplasia, 5(4.4\%) women had ASCUS, 4(3.5\%) women had inflammation and $1(0.9 \%)$ for each of Atrophic virginities, Bloody, LSIL and normal. Pap smear positive as ASCUS and LSIL were $5.3 \%$ of 114 cases because bloody field cases not considered in a calculation.

Table 3: frequency of Pap smear results as stated in the Bethesda system.

\begin{tabular}{ll}
\hline \multicolumn{1}{c}{ Pap Smear } & \multicolumn{1}{c}{ Frequency (\%) } \\
\hline Bloody & $1(0.9 \%)$ \\
\hline Atrophic virginities & $1(0.9 \%)$ \\
\hline Normal & $1(0.9 \%)$ \\
\hline Infection & $88(77.2 \%)$ \\
\hline Inflammation & $4(3.5 \%)$ \\
\hline Metaplasia & $14(12.3 \%)$ \\
\hline ASCUS & $5(4.4 \%)$ \\
\hline LSIL & $1(0.9 \%)$ \\
\hline Total & $115(100 \%)$ \\
\hline
\end{tabular}

Compare results of both Pap smear (golden standard) with visual inspection by 2 by 2 table (table), observe that 1 case in both methods was positive and 77 cases negative in both methods while 5 cases were negative in visual inspection and positive in pap smear and 31 cases were positive in visual inspection and negative in Pap smear. The relationship between Pap smear method and visual inspection method were non-significant with P-value 0.46.

Tests sensitivity were $16.67 \%$, specificity were $71.3 \%$ and positive predictive value $3.13 \%$ were while negative predictive value was $93.9 \%$ for visual inspection comparing with Pap smear. 
Table 4: Relation between visual inspection and Pap smear results for a premalignant disease of the

\begin{tabular}{lllll}
\multicolumn{4}{c}{ cervix } & Total \\
\cline { 3 - 4 } Test & & Pap Smear & \\
\cline { 2 - 4 } & & Positive & Negative & \\
\hline Visual & Positive & 1 & 31 & 32 \\
\cline { 2 - 5 } inspection & Negative & 5 & 77 & 82 \\
\hline Total & & 6 & 108 & 114 \\
\hline
\end{tabular}

Punch biopsy (without colposcopy) done for 32 cases with a positive whitish area, results confirmed dysplasia in only $1 \%$ cases while most of the cases were normal $70 \%$ and $16 \%$ of cases had an infection.

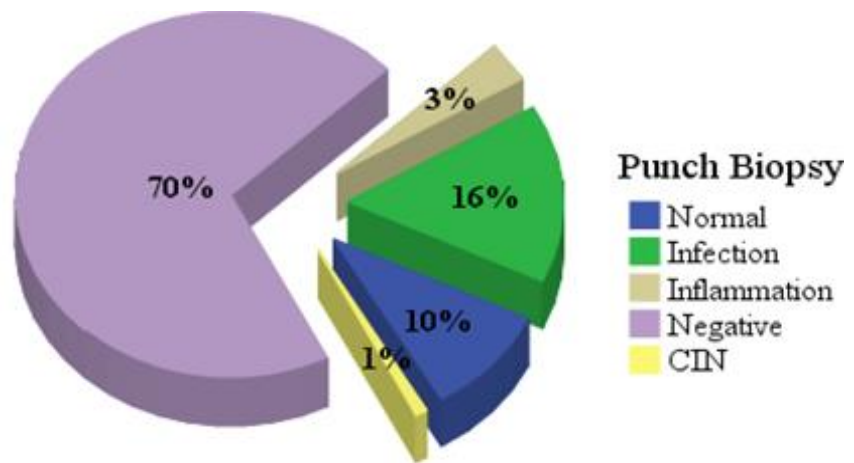

Figure 4: Percentage of punch biopsy results

\section{DISCUSSION}

A total number of cases contained in the current study was 115 women who were referred from clinics by the senior gynaecologist to Obstetrics and Gynecology unit in Maternity Teaching Hospital in Sulaimani, were symptomatic from September 2012 to February 2013.

A women in his study (115 cases), their age ranged from 20 to 50 years old. Current study age group not similar to Khan [14] study at 2007 were age ranged from 25 to 65 years old and Denny carry on a screening in the South African women at the age range from 35 to 65 years old [15].

This study revealed the corresponding number for patients with ASCUS and LSIL were related to parity (range: 2-8) similar to FOTRA results, found that multiparty is by itself is risk factor due to an effect of hormones on cervical epithelium during pregnancy and normal vaginal delivery causes damage to the cervical epithelium [16].

In a Singh [17] study by VIA method among 27 women, 25 cases were diagnosed compare with Pap smear test only 20 cases were noticed. Goel [18] study of 30 dysplasia cases, only in 15 Pap smear cases were positive and by VIA 29 cases and Jeronimo [19] by Pap smear test detected 15 cases over all 35 CIN 1 cases and five cases among 13 CIN 2-3 cases and by visual method diagnosed 20 cases among 35 CIN 1 cases and 11 cases detected on CIN 2-3. CIN lesions cannot be diagnosed by naked eye examination because usually they are asymptomatic and cervix often looks normal. Currently cervical colposcopy and cytology also punch biopsy for colposcopic with direct guided they are only reliable and practical ways for diagnosis. This varies from laboratory to laboratory and one of the main problem is inconsistent reporting with Pap smear test. There are many efforts to standardizing Pap smear reporting for example using the Bethesda system. But still, they are not succeeded and until now there is no universally agreed reporting system. Over all, high-grade squamous intraepithelial lesions (HSILs) are not have any problem such as CIN 2 and CIN 3 in most reporting systems. The problems rise with borderline group for example atypical squamous cells of unknown significance (ASCUS) or atypical glandular cells (AGUS) [20]. 
In the current study results, stated that $5.3 \%$ of Pap smear tests for ASCUS and LSIL was abnormal. Denny [15] stated $8.2 \%$ as an incidence of abnormal Pap smear. A Project in the Zimbabwe University on cervical cancer, they claimed $14.6 \%$ women that participated in their project had an abnormal result by Pap smear test [21]. Megevand reported 13\% Pap smear abnormality in their sample study [22]. Although, Cecchini observed only in $1 \%$ of their study population abnormal Pap smear [23]. Current study showed a lower percentage than those studies might be related to the way of sample collection by wooden Ayre spatula or reading by cytologist and a low number of cases.

In the current study, VIA method for detect dysplasia only one mild case detected at the same time not detected any other dysplasia (mild and severe), however even this mild dysplasia case did not detect by Pap smear. Five cases of ASCUS and only one LSIL case observed by Pap smear but not detected by VIA method. Might preparation of acetic acid way and other materials used for Pap smear have an effect on these results. In the Singh study among 27 cases, by VIA method 25 cases were observed and by Pap smear method 20 cases were observed [17].

In a Goel study among 30 dysplasia cases, in only 15 Pap smear cases were positive and in VIA method 29 positive cases [18]. Jeronimo observed 15 positive CIN 1cases by Pap smear method among 35 and five positive cases among 13 of CIN 2-3 while by VIA method indicate 20 CIN 1 positive cases among 35 and 11 positive cases of CIN2-3 [19].

The biopsy dysplasia (by punch biopsy, without colposcopy) confirmed incidence in the current study was only $1 \%$. Goel stated dysplasia on histopathology $7.5 \%$ confirmed rate in their population study [17] while Jeronimo and Singh dysplasia rate in their studies were $2.49 \%$ and $3.6 \%$, respectively [19]. The difference dysplasia rate between the current study with mentioned studies might related to that these studies included a larger sample comparing to the current study. For the current study, women who came to the hospital tested were those had different symptoms and those might be relate to a high-risk people but biopsy not performed for all patients, only when a whitish area on cervix was seen after acetic acid applied. Furthermore, contributory factors that also might be affected to the low dysplasia rate of confirmed biopsy in the current study.

In the comparison of visual inspection method with Pap smear method in the current study without colposcopy or colposcopy directed guided biopsy, Pap smear method was considered as the standard measure. In the current study, VIA method was performed for all samples and a biopsy was performed if any lesions observed by naked eyes but in other studies for example; Goel study indicate Pap smear method with colposcopy or colposcopy direct guided biopsy as standard measure [18].

The VIA method accuracy (sensitivity) in the current study indicated that to diagnose precancerous lesions was $16.67 \%$, the specificity $71.1 \%$, the positive predictive $3.13 \%$, and the negative predictive $93.3 \%$. Bomfim performed a similar study with colposcopy in Northeast Brazil stated that, if one or more tests were positive performed by specialized for example; nurses or physicians. For the LGSIL and HGSIL, the sensitivity was $100 \%$ for visual method compare to $18 \%$ for Pap smears method and $78 \%$ rate specificity for visual inspection method in comparison with $100 \%$ for Pap smears method. Furthermore, the positive predictive value (PPV) for LGSIL of visual inspection method was $15.6 \%$ and for HGSIL was $2.8 \%$ while visual inspection method negative predictive value (NPV) was a lot more and reported $100 \%$ for each two methods. Positive predictive value (PPV) rate were $97 \%$ and $99 \%$ respectively for Pap smear method. Bomfim reported that visual inspection method might be a very good test for screening for diagnose cervical cancer and indicate that physicians and also nurses are capable of performing visual inspection test assessment. For the current study low sensitivity and high specificity for visual inspection method might relate to these reasons; this study included few numbers of false positives and low number of studied cases also not guided biopsy by colposcopy [24]. 


\section{CONCLUSION}

This study demonstrates that visual inspection test compares to standard Pap smear tests have a low sensitivity with non-significant relation between two methods and visual inspection test must be confirmed by a Pap smear test for screening of premalignant cervical cancer.

\section{REFERENCE}

[1] J. Ferlay, I. Soerjomataram, R. Dikshit, S. Eser, C. Mathers, M. Rebelo, et al., "Cancer incidence and mortality worldwide: sources, methods and major patterns in GLOBOCAN 2012," International journal of cancer, vol. 136, pp. E359-E386, 2015.

[2] S. Rebecca, N. Deepa, and J. Ahmedin, "Cancer statistics, 2012," Ca Cancer J Clin, vol. 62, pp. 10-29, 2012.

[3] D. Saslow, D. Solomon, H. W. Lawson, M. Killackey, S. L. Kulasingam, J. Cain, et al., "American Cancer Society, American Society for Colposcopy and Cervical Pathology, and American Society for Clinical Pathology screening guidelines for the prevention and early detection of cervical cancer," CA: a cancer journal for clinicians, vol. 62, pp. 147-172, 2012.

[4] S. Albert, O. Oguntayo, and M. Samaila, "Comparative study of visual inspection of the cervix using acetic acid (VIA) and Papanicolaou (Pap) smears for cervical cancer screening," Ecancermedicalscience, vol. 6, 2012.

[5] J. M. Walboomers, M. V. Jacobs, M. M. Manos, F. X. Bosch, J. A. Kummer, K. V. Shah, et al., "Human papillomavirus is a necessary cause of invasive cervical cancer worldwide," The Journal of pathology, vol. 189 , pp. 12-19, 1999.

[6] W. Small Jr, M. A. Bacon, A. Bajaj, L. T. Chuang, B. J. Fisher, M. M. Harkenrider, et al., "Cervical cancer: a global health crisis," Cancer, vol. 123, pp. 2404-2412, 2017.

[7] A. B. Miller and W. H. Organization, "Cervical cancer screening programmes: managerial guidelines," 1992.

[8] P. A. Cohen, A. Jhingran, A. Oaknin, and L. Denny, "Cervical cancer," The Lancet, vol. 393, pp. 169-182, 2019.

[9] E. Shepard, "George Papanicolaou: development of the Pap smear," Medical Center Archives of New YorkPresbyterian/Weill Cornell, vol. 2015, 2011.

[10] B. Zahid, N. Khawaja, and R. Tayyeb, "Prevalence of abnormal cervical cytology and its relation with age and parity," Annals of King Edward Medical University, vol. 11, 2005

[11] R. Sankaranarayanan, R. Wesley, S. Thara, N. Dhakad, B. Chandralekha, P. Sebastian, et al., "Test characteristics of visual inspection with $4 \%$ acetic acid (VIA) and Lugol's iodine (VILI) in cervical cancer screening in Kerala, India," International Journal of Cancer, vol. 106, pp. 404-408, 2003.

[12] A. Bhattacharyya, J. Nath, and H. Deka, "Comparative study between pap smear and visual inspection with acetic acid (via) in screening of CIN and early cervical cancer," Journal of Mid-life Health, vol. 6, pp. 53-58, April 1, 20152015.

[13] M. Peiretti, I. Zapardiel, V. Zanagnolo, F. Landoni, C. P. Morrow, and A. Maggioni, "Management of recurrent cervical cancer: A review of the literature," Surgical Oncology, vol. 21, pp. e59-e66, 2012/06/01/ 2012.

[14] S. Khan, R. Jha, and P. R. Pant, "Accuracy of cytology, visual inspection with acetic acid or lugol's iodine in cervical cancer screening," Nepal Journal of Obstetrics and Gynaecology, vol. 2, pp. 48-53, 2007.

[15] L. Denny, "The prevention of cervical cancer in developing countries," BJOG: An International Journal of Obstetrics \& Gynaecology, vol. 112, pp. 1204-1212, 2005.

[16] R. FOTRA, S. GUPTA, and S. GUPTA, "Sociodemographic Risk Factors for Cervical Cancer in Jammu Region of Jand K State of India First Ever Report From Jammu," cancer, vol. 6, p. 8, 2014.

[17] K. Singh and S. More, "Visual inspection of cervix with acetic acid in early diagnosis of cervical intraepithelial neoplasia and early cancer cervix," J Obstet Gynaecol India, vol. 60, pp. 55-60, 2010.

[18] A. Goel, G. Gandhi, S. Batra, S. Bhambhani, V. Zutshi, and P. Sachdeva, "Visual inspection of the cervix with acetic acid for cervical intraepithelial lesions," International Journal of Gynecology \& Obstetrics, vol. 88 , pp. 25-30, 2005

[19] J. Jeronimo, O. Morales, J. Horna, J. Pariona, J. Manrique, J. Rubiños, et al., "Visual inspection with acetic acid for cervical cancer screening outside of low-resource settings," Revista panamericana de salud pública, vol. 17, pp. 1-5, 2005.

[20] F. Lim, "Management of premalignant lesions of the cervix," ANNALS-ACADEMY OF MEDICINE SINGAPORE, vol. 31, pp. 357-365, 2002.

[21] L. Gaffikin, P. Blumenthal, J. McGrath, and Z. Chirenje, "Visual inspection with acetic acid for cervicalcancer screening: Test qualities in a primary care setting," The Lancet, vol. 353, p. 869, 1999.

[22] E. Megevand, L. Denny, K. Dehaeck, R. Soeters, and B. Bloch, "Acetic acid visualization of the cervix: an alternative to cytologic screening," Obstetrics \& Gynecology, vol. 88, pp. 383-386, 1996.

[23] S. Cecchini, R. Bonardi, A. Mazzotta, G. Grazzini, A. Iossa, and S. Ciatto, "Testing cervicography and cervicoscopy as screening tests for cervical cancer," Tumori Journal, vol. 79, pp. 22-25, 1993.

[24] S. Bomfim, E. Santana-Franco, and L. Bahamondes, "Visual inspection with acetic acid for cervical cancer detection," International Journal of Gynecology \& Obstetrics, vol. 88, pp. 65-66, 2005. 